\title{
Orientação nutricional no pré-natal: estudo com nutrizes no pós-parto hospitalizadas em uma maternidade pública
}

Nutritional orientation in prenatal care: a study with postpartum nurses hospitalized in a public maternity hospital

\section{Francisca Juscicléia de Pinho Silva Leal}

Nutricionistas. Centro Universitário de Ciências e Tecnologia do Maranhão - UNIFACEMA, 65606020, Caxias-MA, Brasil.

\section{Josiane da Rocha Silva Ferraz}

Nutricionista. Especialista. Prescrição de Fitoterápicos e Suplementação Nutricional Clínica e Esportiva. Universidade Estácio de SáUNESA, Brasil.

\section{Joyce Lopes Macedo}

Nutricionistas. Centro Universitário de Ciências e Tecnologia do Maranhão - UNIFACEMA, Caxias-MA, Brasil.

\section{Daisy Jacqueline Sousa Silva}

Nutricionista. Especialista. Nutrição Clínica Funcional. Faculdade Santo Agostinho- FSA, 64019-625, Teresina-PI, Brasil.

\section{Resumo}

O objetivo do presente estudo foi identificar as orientações nutricionais concedidas as nutrizes durante o período gestacional. Corresponde a um estudo descritivo de abordagem transversal e caráter quantitativo realizado entre os meses de julho e agosto de 2018, com mulheres no pós-parto de uma maternidade pública do estado do Maranhão. A amostra foi composta por 133 nutrizes com idade maior ou igual 18 anos e que aceitaram participar da pesquisa, os dados foram analisados por meio de variáveis fundamentadas no programa IBM SPSS onde, a partir daí foi possível a obtenção de gráficos e tabelas. O estudo mostrou que das 133 participantes, $88,0 \%$ realizaram mais de cinco consultas de pré-natal, $84,2 \%$ receberam informações sobre alimentação e aleitamento materno e $81,2 \%$ receberam informações sobre a diminuição do consumo de industrializados, e quando questionadas sobre a importância da alimentação saudável na gestação, todas relataram ser muito importante. Dentre os nutrientes investigados, conclui-se que o ferro e ácido fólico na forma de medicamento foram os que mais orientados, devido sua importância para o fechamento do tubo neural e combate a anemia. O profissional que mais repassou informações durante o pré-natal foi o enfermeiro, seguido pelo médico e nutricionista, isso devido ao maior contato que esse profissional possui dentro da assistência pré-natal no local estudado.

Palavras-chave: Gestação, Nutrientes, PréNatal. 


\section{Abstract}

The objective of the present study was to identify the nutritional guidelines given to the nursing mothers during the gestational period. Corresponds to a descriptive study of transversal approach and quantitative character carried out between the months of July and August of 2018, with women in the postpartum period of a public maternity hospital in the state of Maranhão. The sample consisted of 133 nursing mothers aged 18 years or more who accepted to participate in the study. Data were analyzed using variables based on the IBM SPSS program, where it was possible to obtain charts and tables. The study showed that of the 133 participants, $88.0 \%$ performed more than five prenatal consultations, $84.2 \%$ received information

\section{Introdução}

A gestação é um fenômeno fisiológico que provoca uma série de transformações no organismo da mulher, sendo necessário uma maior oferta de nutrientes, uma vez que suas necessidades nutricionais encontram se elevadas. Caso não haja uma oferta adequada de nutrientes nesse período haverá uma competição materno-fetal, o que prejudicará o desenvolvimento saudável do feto. ${ }^{1}$

A influência de uma alimentação adequada, durante todo período gestacional é evidente e se relaciona com o trabalho de parto, evita complicações durante o puerpério, favorece a lactação e possibilita ao recém-nascido um bom estado nutricional. Portanto, as gestantes necessitam de um aporte adicional de nutrientes para o crescimento e desenvolvimento fetal e manutenção de suas reservas teciduais. ${ }^{2}$ Dentre os nutrientes necessários durante este período, about feeding and breastfeeding, and $81.2 \%$ received information about decreased consumption of industrialized products, and when questioned about the importance of healthy eating during pregnancy, all reported to be very important. Among the nutrients investigated, it was concluded that iron and folic acid in the form of medication were the most oriented, due to their importance for the closure of the neural tube and the fight against anemia. The professional who provided the most information during prenatal care was the nurse, followed by the doctor and nutritionist, due to the greater contact that this professional has within prenatal care at the place studied.

Keywords: Gestation, Nutrients, Prenatal.

o ferro, vitamina A, ácido fólico, Zinco e ômega 3 apresentam-se como benéficos para 0 bom desenvolvimento da gestação e consequentemente do feto. ${ }^{3}$

A deficiência de ferro é a causa mais comum de anemia carencial no mundo, constituindo-se a carência nutricional de maior amplitude afetando principalmente crianças e gestantes de países em desenvolvimento. A deficiência/insuficiência de vitamina $A$, pode provocar cegueira noturna, e está associada com risco cinco vezes maior de mortalidade materna nos dois anos pós-parto, sendo importante seu consumo durante esse período, pois a mulher necessita de um maior aporte desse nutriente para manutenção da saúde e para o desenvolvimento fetal. ${ }^{4}$

O ácido fólico atua na prevenção da ocorrência de defeitos no fechamento do tubo neural na 
gestação, possuindo papel fundamental na biossíntese de purinas e pirimidinas e na formação do DNA e RNA, aspecto indispensável ao desenvolvimento fetal, o consumo inadequado pode ocasionar alterações no DNA e nos cromossomos. ${ }^{5}$ A carência de zinco no período gestacional está relacionada com aborto espontâneo, retardo do crescimento intrauterino, prejuízo na função dos linfócitos $T$ e anormalidades congênitas além de apresentarem efeitos no sistema hormonal que controla o crescimento após o nascimento do bebê. ${ }^{6}$

O uso de alimentos ou suplementos que contenham ácido graxo ômega-3 torna-se imprescindível durante a gestação, o feto obtém esse ácido graxo por meio exclusivamente do transporte placentário e isso só se tornará possível se as gestantes fizerem uso desse nutriente, recomenda-se a introdução de peixes 2-3 vezes durante a semana ao longo do período gestacional. ${ }^{7}$

A assistência pré-natal é um elemento decisivo para a continuação adequada da gestação, pois possibilita prevenir, diagnosticar e tratar algum problema que possa vir a ocorrer durante esse período. Considera-se que se houver uma assistência pré-natal de forma eficaz durante esse período, com todos os recursos indispensáveis para sua execução, como recursos humanos e financeiros, haverá uma melhoria significativa no desfecho final desse processo. ${ }^{8}$

Dessa forma, torna-se imprescindível que a gestante tenha um acompanhamento nutricional eficaz, além de médicos e enfermeiros, a presença do nutricionista é indispensável, visto que ele é o profissional habilitado para prestar as devidas orientações nutricionais para as gestantes.

Diante do que foi exposto, o objetivo geral do estudo é identificar as orientações nutricionais concedidas às nutrizes durante $o$ período gestacional.

\section{Metodologia}

A presente pesquisa de campo corresponde a um estudo de abordagem quantitativa descritiva do tipo transversal, com mulheres no pós-parto.

Realizou-se o estudo entre os meses de julho a setembro de 2018 em uma maternidade pública de um município do estado do Maranhão, referência em mais de 50 municípios da macrorregião. A unidade possui 50 leitos para as gestantes e 5 berçários, conta ainda com a unidade de Terapia Intensiva (UTI) neonatal com 11 leitos e banco de leite humano.

A amostra foi composta por 133 nutrizes no pós-parto com idade igual ou superior a 18 anos, que realizaram seu pré-natal no referido município ou nos municípios vizinhos, tiveram seus filhos na maternidade pesquisada e assinaram o Termo de Consentimento Livre e Esclarecido (TCLE), a coleta de dados foi realizada por conveniência, no momento em que elas se encontravam nas enfermarias, onde nesse momento os objetivos do estudo foram 
informados. Foram excluídas do estudo, nutrizes que tiveram seus filhos em outras instituições, que possuíam idade inferior a 18 anos e que por complicações pós-parto, não puderam responder ao questionário.

Na presente pesquisa, utilizou-se de um questionário estruturado elaborado pelos pesquisadores, no qual continha 17 perguntas que abrangiam dados relativos ao comparecimento das nutrizes no pré-natal, quantidade de consultas realizadas, orientações sobre amamentação, aleitamento materno, consumo alimentar de ferro, ácido fólico e ômega-3, consumo medicamentoso de ferro, vitamina $A$, zinco, ácido fólico e ômega-3, além de questões relativas ao consumo de industrializados, quantidade de refeições realizadas, diminuição no consumo de gorduras, período mínimo para oferta de aleitamento materno, mudança na alimentação e perguntas relacionadas a percepção das nutrizes sobre alimentação saudável na gestação.

Os dados foram obtidos por meio de variáveis fundamentadas no questionário e analisados por meio do programa IBM SPSS. Todas as variáveis foram nominais, já que as respostas não necessitaram de ordenação de categorias, após coleta de dados foram incluídos todas as respostas e seus respectivos valores, onde a partir daí foi possível se obter tabelas por meio das ferramentas estatísticas descritivas e frequências.

A coleta de dados iniciou-se somente após aprovação pelo Comitê de ética em pesquisa com seres humanos (CEP), por meio da Plataforma Brasil, seguindo a resolução do $\mathrm{n}$ 은 466/2012, com respectivo número de CAAE: 01748818600008007. no 466 de 12 de dezembro de 2012.

\section{Resultados e Discussão}

A tabela 01 mostra a relação das consultas realizadas, quantidade de consultas e orientações recebidas pelas nutrizes sobre alimentação e aleitamento materno, $64,6 \%$ das nutrizes referiram terem iniciado as consultas de pré-natal ainda no primeiro trimestre de gestação e apenas 35,3\% relataram início após esse período. Em relação à quantidade de consultas realizadas houve um maior percentual de consultas realizadas, maior que 5 vezes. Quanto ao recebimento de orientações sobre aleitamento materno exclusivo e alimentação saudável, 84,2\% referiram terem recebido essas orientações e o correspondente a 15,8\% não receberam quaisquer informações sobre alimentação saudável e aleitamento materno exclusivo.

Krause e colaboradores ${ }^{7}$ avaliaram a percepção das gestantes sobre o pré-natal, das 14 participantes, $57,14 \%$ referiram ter iniciado o acompanhamento de pré-natal ainda no primeiro trimestre. Segundo os autores, este fato não parece ser um dado muito positivo tendo em vista que a mídia constantemente propaga informações sobre a importância precoce das consultas de pré-natal e seus benefícios, o que pode ter influenciado na 
adesão das gestantes as consultas. Ainda de acordo com o estudo, as gestantes que iniciaram o pré-natal após o 1 ำ trimestre tiveram um menor número de consultas o que não é benéfico para a mãe e o bebê.

Resultados do estudo de Domingues e colaboradores $^{8}$ ressaltam a importância de que o número mínimo de consultas de pré-natal preconizadas pela Organização Mundial de Saúde (OMS) devem ser seguidas, prevenindo assim a mortalidade perinatal, nessas consultas é torna-se possível o diagnóstico e tratamento de enfermidades que possam vir a ocorrer, trazendo prejuízos a saúde da gestante e do feto.

O recebimento de orientações sobre aleitamento materno, observado em pesquisa realizada por Urbanetto e colaboradores ${ }^{9}$ mostram que de 11 participantes apenas 4 puérperas receberam orientações no pré-natal, porém, com dificuldade de compreensão por parte das gestantes, o que ocasiona uma barreira para a efetividade do aleitamento materno exclusivo. Resultados contrários ao presente estudo, em que $84,2 \%$ das entrevistadas referiram terem recebido essa informação em suas consultas e sem relatos de dificuldades de assimilação dos conhecimentos repassados.

Um pré-natal realizado de forma efetiva, contribui para um bom desfecho da gestação, uma vez que orientações repassadas nessas consultas abordando entre outros assuntos o aleitamento materno exclusivo e promoção de ações educativas com as gestantes ajudará na sua adesão e posterior reprodução dos conhecimentos repassados, o que favorece a prática do amamentar. ${ }^{10}$

O Aleitamento Materno Exclusivo é primordial para o bom desenvolvimento do bebê, além de protegê-lo contra alergias e cólicas, é adequado em todos os nutrientes que a criança necessita nos primeiros 6 meses de vida, e fortalece o contato entre mãe e filho. ${ }^{11} A$ literatura cita que vários fatores contribuem para a saúde do recém-nascido, entre os quais, a alimentação adequada durante o período gestacional é importante para o feto, que se alimenta exclusivamente através dos nutrientes provenientes da dieta da mãe. ${ }^{12}$

A segunda parte da entrevista, buscou verificar se as nutrizes receberam informações quanto ao consumo de alimentos fontes de nutrientes, necessários ao bom desenvolvimento gestacional, tais como: ferro, ácido fólico e ômega-3, os resultados encontram-se na tabela 2.

Em relação ao consumo de alimentos fontes de ferro, $85 \%$ das nutrizes declararam terem recebido essa informação em suas consultas de pré-natal, e apenas $15 \%$ das entrevistadas não foram orientadas sobre o consumo. Na pesquisa, $63,9 \%$ das nutrizes afirmaram que foram indicadas a consumirem alimentos fontes de ácido fólico e 36,1\% não foram orientadas, já em relação ao consumo de fontes de ômega -3, $61,7 \%$ referiram terem recebido essa informação e uma pequena parcela das entrevistadas, $38,3 \%$, não tiveram acesso a tal informação. 
Santos ${ }^{13}$ em sua pesquisa verificou o consumo alimentar de energia e nutrientes no 1 으 e 3 은 trimestre de gestação, e observou que em relação aos macros e micronutrientes não se obteve resultados diferentes na categoria peso ao nascer. Entretanto, o estudo relata que houve diferenças significativas entre o consumo de ferro e ácido fólico no último trimestre da gestação e que as gestantes que realizaram um consumo adequado desses micronutrientes tiveram filhos com peso adequado comparados aquelas que tiveram um consumo inadequado ao longo da gestação.

Azevedo, Roediger e Szarfarc ${ }^{14}$ avaliaram a percepção das causas de anemia em gestantes atendidas no programa estratégia saúde da família e constataram que todas as entrevistadas não possuíam nenhum conhecimento sobre anemia e os malefícios que a mesma pode ocasionar na vida da mãe e do bebê, apesar de estarem comparecendo as consultas de prénatal, $92 \%$ das nutrizes relataram não ter recebido quaisquer informação nutricional durante todo o pré-natal. Os autores concluíram que quando essas orientações são repassadas de forma eficaz podem contribuir para o bem-estar da gestante e do filho, uma vez que, conhecendo os benefícios de uma alimentação adequada durante toda a gestação a mulher pode modificar seus hábitos através de escolhas mais saudáveis.

Além de consumir alimentos fontes de ferro, é importante que a gestante faça uso de suplementos com esse composto. Fazio e colaboradores ${ }^{15}$ em estudo sobre o consumo dietético do ferro por gestantes e ganho ponderal materno após o aconselhamento nutricional, observaram que o consumo do referido micronutriente somente por meio da alimentação não foi suficiente para suprir à quantidade requerida pela mãe e o feto durante o período gestacional.

A pesquisa de Magalhães ${ }^{16}$ evidenciou que mulheres que apresentaram um consumo abaixo do recomendado de ômega 3 demonstraram um aumento na propensão de desenvolvimento de sintomas relacionados a depressão, pois atuam como substrato para a síntese de mediadores antiinflamatórios, favorece a produção de tromboxanos e prostaglandinas E2, e colabora para tempos de gestação prolongados e maior peso ao nascer.

A terceira parte da entrevista teve por finalidade averiguar se as nutrizes receberam orientações com incentivo ao não consumo de alimentos industrializados, número de refeições que devem ser realizadas por dia e diminuição no consumo de fontes de gordura na alimentação (Tabela 3).

Em relação a primeira variável $81,2 \%$ das nutrizes referiram terem recebido essa informação durante suas consultas e apenas $18,8 \%$ não foram instruídas a redução no consumo desses alimentos. Em relação à quantidade de refeições realizadas por dia, 
73,7\% das nutrizes referiram realizar, por orientação dos profissionais, mais de cinco refeições e 26,3 \% não foram orientadas a realizar essa quantidade de refeições .Quando perguntadas sobre a redução do consumo de produtos gordurosos $67,7 \%$ das entrevistadas referiram terem feito essa redução por indicação dos profissionais de saúde e 32,3\% não receberam tal orientação.

Observa-se que com o crescimento da população associado ao fácil acesso à alimentos industrializados como, produtos ricos em sódio, gorduras e açúcares, houve aumento na ingestão deste tipo de alimentos entre os indivíduos, principalmente durante a gestação, pois nessa fase a gestante tem aumento de apetite, e opta muitas vezes por alimentos de fácil acesso como é o caso dos industrializados, o que contribui para o ganho de peso. ${ }^{17}$

Rodrigues e colaboradores ${ }^{18}$ em estudo realizado em uma clínica escola na cidade de Maceió-AL, buscaram verificar entre outros parâmetros, o estado nutricional de gestantes de alto risco e mostraram que as gestantes que se encontravam nessa situação possuíam consumo elevado de produtos industrializados, ricos em gorduras trans e saturada.

Desta forma, torna-se necessário que durante essa fase de gestação a mulher adeque sua alimentação, opte sempre por alimentos naturais como frutas e verduras, e evite o consumo de alimentos prejudiciais à saúde como os industrializados, que apresentam em sua composição substâncias maléficas ao organismo. ${ }^{19}$

Devido às modificações causadas pela gestação, é importante que durante todo o período gestacional, a gestante possua uma alimentação adequada, realize o fracionamento correto das refeições consumidas, pois Ihe ajudará na diminuição de desconfortos gástricos como a azia, decorrente da diminuição dos espaços devido ao aumento uterino. ${ }^{20}$

Resultados contrários a presente pesquisa foram observados no estudo de Gomes ${ }^{21}$ onde avaliou as práticas alimentares de gestantes e mulheres não grávidas e observou que em relação às práticas alimentares das gestantes, das 253 participantes entre gravidas e não gravidas, apenas $16,4 \%$ das gestantes realizavam a ingestão de alimentos fritos em gordura em relação a $21,9 \%$ que nunca ou raramente realizavam essa prática.

Houve um maior predomínio na suplementação medicamentosa de ferro e ácido fólico 96,2\% e 90,2\%, respectivamente e baixa orientação quanto ao consumo de zinco, ômega 3 e vitamina A, 85,7\%, 90,2\% e 75,2\% respectivamente. As nutrizes que não consumiram esses medicamentos relataram que foram orientadas a consumirem durante a gestação (Tabela 4).

A não suplementação de ferro pode provocar intercorrências pra a gestante e para o feto, como aborto espontâneo, partos prematuros, 
hemorragias durante o trabalho de parto, hipóxia, recém-nascido ( $R N$ ) com peso insuficiente ao nascer, anemia para o $\mathrm{RN}$, sistema imunológico baixo. ${ }^{22}$

A carência de vitamina A está relacionada a uma dificuldade na produção dos eritrócitos, também conhecidos como células vermelhas do sangue além de prejudicar o equilibro da concentração de ferro no corpo, essa redução dos níveis de hemoglobina e retinol se explica pela correlação entre a baixa concentração de retinol e menores níveis de ferritina. A deficiência de zinco também prejudica a absorção de vitamina $A$, influenciando em sua absorção, transporte e posterior utilização, pois o zinco age diminuindo a concentração de vitamina A circulante, ocasionando prejuízos na função desse micronutriente mesmo este estando com reservas hepáticas satisfatórias e isso pode ser explicado, em parte, pela participação do zinco na síntese da proteína. ${ }^{23}$

Em estudo realizado por Barbosa e colaboradores ${ }^{10}$ buscaram verificar os fatores associados ao uso de ácido fólico durante a gestação, mostraram que algumas situações comprometem o uso dos suplementos necessários para o desenvolvimento adequado do feto, pela gestante, tais como, renda, gravidez não preparada e o baixo comparecimento as consultas de pré-natal, estas situações segundo os autores corroboraram para o desfecho desfavorável do uso de folato na gestação.
A importância do folato é amplamente relatada na literatura devido sua necessidade para o desenvolvimento do feto nas primeiras semanas de gestação, pois é primordial no processo de síntese de DNA, devendo a mãe obter através de uma alimentação balanceada quantidades suficientes para suprir os requerimentos para a formação do embrião. ${ }^{24}$

Moura e Azevedo ${ }^{25}$ relatam em seu estudo, que além de uma alimentação adequada durante a gestação, o uso de suplemento rico em ômega 3 é essencial, pois esse nutriente será repassado através da placenta para o feto principalmente no último trimestre da gestação, e após o nascimento do bebê, passará a consumi-lo por meio do leite materno.

A suplementação de zinco é utilizada a fim de diminuir o estresse oxidativo, citocinas inflamatórias e aumentar os níveis de proteínas pró-inflamatórias. Mecanismos adaptativos permitem ao organismo manter as concentrações de zinco total normal, mas a deficiência pode ocorrer devido à redução da absorção ou aumento das perdas gastrointestinais. $^{26}$

A vitamina A participa de vários processos metabólicos, atua no sistema imunológico auxiliando no combate as infecções. $\mathrm{Na}$ gestação, é importante na proliferação e diferenciação celular e ajuda no adequado crescimento e desenvolvimento fetal e bom funcionamento da visão. ${ }^{27}$ 
O aleitamento materno exclusivo deve ser oferecido até o sexto mês de vida do bebê, pois além de ajudar no desenvolvimento imunológico, previne infecções, diarreia e cólicas. Pensando nisso, as entrevistadas foram perguntadas sobre o período em que deveriam amamentar.

Questionadas sobre o período em que deveriam amamentar, $80,5 \%$ das entrevistadas relataram possuir conhecimentos sobre o período mínimo para o aleitamento materno exclusivo e apenas 19,5\% não souberam relatar tal informação.

Está amplamente relatado na literatura os benefícios do aleitamento materno exclusivo até $06^{\circ}$ mês de vida pós-parto, quando ofertado adequadamente sem a introdução de outras fontes alimentares, promove o crescimento e desenvolvimento adequado do feto, o contato mãe e filho, além de ser o alimento adequado fisiologicamente ao bebê. ${ }^{28}$

Estudo realizado por Carvalho ${ }^{29}$, demonstrou que $21,20 \%$ das entrevistadas possuíam conhecimento sobre essa orientação, resultados similares foram encontrados no presente estudo, onde $80,5 \%$ das nutrizes possuíam conhecimento sobre o período em que deveriam ofertar o leite materno exclusivo.

Quando questionadas sobre mudanças na alimentação durante a gestação, $80,5 \%$ das entrevistadas relataram terem realizado algum tipo de mudança, sendo esta, em sua maioria na quantidade (Tabela 5).
O consumo alimentar durante a gestação encontra-se elevado devido a um acréscimo no requerimento de energia para formação do embrião, em vista disso, torna-se necessário que durante essa fase, a mulher realize algumas mudanças na quantidade e na qualidade do que ingere, visando o bem-estar do feto. ${ }^{27}$

Todas as 133 participantes $(100,0 \%)$ referiram que uma alimentação adequada durante a gestação é muito importante para o prosseguimento adequado da gestação contribuindo para o adequado desenvolvimento do feto.

Resultados contrários a estes foram encontrados em um estudo realizado por Gama e colaboradores ${ }^{30}$ quando questionadas sobre o que em sua percepção seria uma alimentação saudável na gestação as mesmas não souberam responder, o que comprova que as orientações dos profissionais de saúde não estão sendo repassados de forma eficaz para o seu público alvo.

Estudos comprovam que vários fatores são levados em consideração pelas gestantes na hora da escolha dos alimentos e como estes serão utilizados, entre eles a renda, crenças, tabus e o desconhecimento sobre os benefícios que os mesmos possuem para o organismo, servem como barreira para a adesão de práticas saudáveis no período gestacional. ${ }^{12}$

A alimentação adequada, constituída pela ingestão de diversos tipos de alimentos fontes 
dos mais variados nutrientes, exerce função indispensável para a saúde do indivíduo a exemplo da gestação. A alimentação e a nutrição são quesitos indispensáveis para atender às necessidades das gestantes obtendo melhores resultados sobre a saúde da mulher e da criança. ${ }^{31}$

Em relação aos profissionais que se sobressaíram nas orientações nutricionais durante as consultas de pré-natal, houve uma predominância de enfermeiro $(57,1 \%)$, seguido pelos médicos $(24,8 \%)$ e nutricionista $(18,0 \%$.).

A maior quantidade de orientações repassadas pelo enfermeiro pode ser explicada pelo fato da maior acessibilidade desse profissional nas consultas de pré-natal, promovendo um acolhimento e escuta, pois ele realiza todo o acompanhamento da gestante desde o início, sendo encaminhado para o nutricionista muitas vezes, quando a gestante já possui algum problema de saúde. Como diabetes gestacional e ganho de peso além do recomendado encaminhando as para adequação da dieta. Ressalta-se que na referida maternidade, não existe a presença de um profissional de nutrição especialista na área de materno-infantil. ${ }^{32}$

A atuação do profissional nutricionista na assistência de pré-natal é de extrema importância, pois é o profissional habilitado para repassar com maior riqueza sobre alimentação saudável, enfatizando que por meio de uma alimentação equilibrada quanti e qualitativamente, é possível se prevenir complicações futuras e promover um crescimento uterino satisfatório. ${ }^{33}$

Em um estudo realizado por $\mathrm{Mello}^{34}$ avaliou o Conhecimento das gestantes sobre as ações que o nutricionista realiza no pré-natal e mostrou que de acordo com as entrevistadas, a presença do nutricionista é fundamental, pois esse profissional é capacitado para tirar dúvidas sobre os alimentos que podem ser consumidos e os que não são indicados. Ainda segundo o mesmo estudo, quinze gestantes relataram que o papel do nutricionista se iguala ao trabalho realizado pelo médico e enfermeiro e que a presença de ambos na assistência pré-natal só agregará benefícios as gestantes.

Assim, enfatiza-se a importância da orientação nutricional e do acompanhamento nutricional nessa fase para fomentar a discussão dos mitos e tabus nesse período, bem como esclarecer o papel dos nutrientes para garantia da segurança alimentar e nutricional da mãe e do seu concepto. Para que o desenvolvimento fetal e peso ao nascer sejam adequados é necessário manter durante a gestação uma alimentação variada e rica em alimentos fontes de macronutrientes e micronutrientes que contribuem para o crescimento intra-uterino. ${ }^{35}$

\section{Conclusão}

O presente estudo demonstrou que houve um bom percentual do comparecimento precoce nas consultas de pré-natal, com quantidades similares as preconizadas pela OMS, fator esse que 
contribui para o prosseguimento adequado da gestação, pois nessas consultas que esclarecidas todas as dúvidas pertinentes a gestação.

As orientações mais repassadas foram sobre o consumo de ferro e ácido fólico na forma medicamentosa, tendo em vista que estes correlacionam-se com o adequado fechamento do tubo neural e para prevenção de anemia e riscos de partos prematuros.

Houve um bom percentual de orientações também em relação a diminuição do consumo de industrializados e fracionamento correto das refeições. A maioria das nutrizes relataram realizar algum tipo de mudança na alimentação, sendo estas em sua maioria na quantidade consumida.

A importância da alimentação saudável na gestação foi relatada por todas as entrevistadas como sendo muito importante para o prosseguimento adequado da gestação e bom desenvolvimento do feto.

Houve um maior predomínio nas orientações repassadas pelos enfermeiros, isso pode ser explicado pelo maior contato que esse profissional possui com as gestantes durante $o$ período gestacional, e principalmente pela falta de um profissional nutricionista especialista na área de materno infantil, o qual é o profissional habilitado para realizar as orientações referentes a necessidades nutricionais.

Para tanto, torna-se necessário que a presença do nutricionista dentro da assistência pré-natal seja constante e permanente, realizando palestras sobre alimentação saudável no período gestacional, desmitificando mitos sobre os alimentos que a gestante deve fazer uso e realizando a avaliação do estado nutricional da gestante.

A presença desse profissional é fundamental também dentro dos serviços desenvolvidos pelo banco de leite Humano, incentivando o aleitamento materno, garantindo a qualidade higiênico-sanitária do leite humano, promovendo orientação, educação e assistência alimentar e nutricional as mães de acordo com a resolução do CFN №200/1998.

\section{Referências}

1. Brognoli AF, Neme LCLH, Passoni CMS. Relação da dieta de gestantes com o estado nutricional. Cadernos da Escola de Saúde. 2017; 1(3):1-14.

2. Baião MR, Deslandes SF. Práticas alimentares na gravidez: um estudo com gestantes e puérperas de um complexo de favelas do Rio de Janeiro (RJ, Brasil). Ciência \& Saúde Coletiva. 2010; 15(1): v. 15, p. 3199-3206.

${ }^{3}$. Linhares AO, Cesar JA. Suplementação com ácido fólico entre gestantes no extremo Sul do Brasil: prevalência e fatores associados. Ciência \& Saúde Coletiva. 2017; 22(1):535-542.

${ }^{4}$. Sousa AL. Análise da concentração de retinol no soro e leite colostro de puérperas com diabetes mellitus gestacional. 2018. Trabalho de Conclusão de Curso. Universidade Federal do Rio Grande do Norte.

${ }^{5}$. Ferraz L et al. Micronutrientes e sua importância no período gestacional. Saber Científico. 2018; 7(1):68-82. 
${ }^{6}$. Cabral AR et al. A suplementação de ácido fólico na prevenção de disfunções autonômicas cardíacas e de anomalias do tubo neural: uma revisão sistemática. Rev Bras Nutr Clin 2015; 30(4): 344-353.

${ }^{7}$. Krause KMO et al. Percepção das gestantes sobre o pré-natal em um centro de atendimento do interior do sul do Brasil. Aletheia. 2017; 50(1-2):21-37.

${ }^{8}$. Domingues RMSM et al. Avaliação da adequação da assistência pré-natal na rede SUS do Município do Rio de Janeiro, Brasil. Cadernos de Saúde Pública. 2012; 28(1):425-437.

${ }^{9}$. Urbanetto PDG et al. Orientações recebidas pelas gestantes no pré-natal acerca da amamentação. Ciência, Cuidado e Saúde. 2017; 16(4):1-8.

10. Barbosa L et al. Fatores associados ao uso de suplemento de ácido fólico durante a gestação. Rev bras ginecol obstet. 2011; 33(9):246-251.

11. Bueno KCVN. A importância do aleitamento materno exclusivo até os seis meses de idade para a promoção de saúde da mãe e do bebê. 2013. Trabalho de Conclusão de Curso. Universidade Federal de Minas Gerais.

12. Bueno AA, Beserra JAS, Weber ML. Características da alimentação no período gestacional. Life Style. 2016 ; 3(2):29-42.

${ }^{13}$. Santos TRS. Consumo alimentar de energia e nutrientes no 1ㅇ e 3 trimestres gestacionais e peso ao nascer: coorte NISAMI. 2018. Trabalho de Conclusão de Curso. Universidade Federal da Bahia.

14. Azevedo BAR, Almeida MF, Szarfarc S. Percepção das causas e riscos da anemia de gestantes atendidas em Programa Estratégia de Saúde da Família em São Caetano do Sul-SP. Segurança Alimentar e Nutricional. 2011; 23(2):984-992.

${ }^{15}$. Fazio ES et al. Consumo dietético de gestantes e ganho ponderal materno após aconselhamento nutricional. Revista Brasileira de Ginecologia e Obstetrícia. 2011;33(2):87-92.

${ }^{16}$. Magalhães DMO. Avaliação da ingestão de ácidos gordos polinsaturados ómega 3 numa amostra de grávidas. 2017. Dissertação [Mestrado]. Universidade do Porto.

17. Matos S et al. Consumo alimentar de gestantes atendidas em uma unidade de saúde de Porto Alegre e sua relação com a idade. Clinical and biomedical research. 2017.

${ }^{18}$. Rodrigues AFC et al. Perfil nutricional de gestantes de alto risco atendidas numa clínica escola de nutrição de Maceió-AL e incentivo ao aleitamento materno. Entre Aberta Revista de Extensão. 2015; 1(1).

${ }^{19}$. Cruz IFS. Alegações maternas para o desmame precoce. 2017. Trabalho de Conclusão de Curso. Universidade Federal de Brasília.

20. Amorin SMR. Fernandes. Perfil Nutricional de Gestantes Atendidas por Duas Unidades Básicas de Saúde de Londrina-PR. Journal of Health Sciences. 2015; 10(2).

${ }^{21}$. Gomes CB. Práticas alimentares de gestantes e mulheres não grávidas: há diferenças? Rev Bras Ginecol Obstet. 2015; 37(7):325-332.

22. Schafaschek H et al. Suplementação de sulfato ferroso na gestação e anemia gestacional: uma revisão da literatura. Arquivos Catarinenses de Medicina. 2018;47(1):198-206

23. Freitas BAC. Restrição do crescimento extrauterino, amamentação e avaliação da adesão e influência da suplementação com micronutrientes nas prevalências de deficiências de ferro, zinco e vitamina a em prematuros. 2015. Tese de Doutorado. Universidade Federal de Viçosa.

${ }^{24}$. Silva RVM, Soares LG, Boeck SC. A utilização do ácido fólico durante o período gestacional como método profilático aos danos da Síndrome Congênita do Zika vírus. Mostra IFTec em Resumos. 2018.

${ }^{25}$. Moura AR, Azevedo FHC. Evidências Científicas Sobre a Alimentação de Gestantes. Saúde em Foco. 2018; 5(1):78-90.

${ }^{26}$. Moura MSBM. Efeito da suplementação com zinco na resposta inflamatória em pacientes com retocolite ulcerativa. 2017. Dissertação [Mestrado]. Universidade Federal do Piauí.

27. Silva NMA. Efetividade das orientações de enfermagem na consulta de pré-natal para aleitamento materno exclusivo. 2017.

${ }^{28}$. Mendonça CPS et al. Avaliação do grau de conhecimento das gestantes quanto a saúde oral do bebê atendidas em uma unidade básica de saúde. Revista Interfaces: Saúde, Humanas e Tecnologia. 2015; 3(8):1-5.

${ }^{29}$. Carvalho JLS et al. Conhecimento das mães sobre aleitamento materno exclusivo e alimentação complementar. Saúde em Redes. 2017; 2(4):383-392.

30. Gama SGN et al. Fatores associados à assistência pré-natal precária em uma amostra de puérperas adolescentes em maternidades do Município do Rio de Janeiro, 1999-2000. Cadernos de Saúde Pública. 2004; 20(1):101-111. 
31. Maciel C, Lima Z, Terrazzan AC. Papel da colina na gestação humana: Revisão da literatura. Brazilian Journal of Development. 2017; 3(3):481-492.

32. Matos DS, Rodrigues MS, Rodrigues TS. Atuação do enfermeiro na assistência ao pré-natal de baixo risco na estratégia saúde da família em um município de Minas Gerais. Enfermagem Revista. 2016; 16(1):18-33.

33. Cançado IAC, Pereira FM, Fernandes RM. Avaliação do conhecimento em nutrição de gestantes atendidas pela Estratégia de Saúde da Família (ESF) da cidade de Pará de Minas-MG. Revistal digital FAPAM. 2016; 1(1):318-327.

${ }^{34}$. Melo ASO et al. Estado nutricional materno, ganho de peso gestacional e peso ao nascer. Revista Brasileira Epidemiologia. 2010; 10(2).

35. Silva JEA, Pacífico ACL, Costa SS. Orientação nutricional no pré-natal e sua importância para uma gestação saudável: relato de experiência. Revista Saúde-UNG-Ser. 2017; 10(1):111.

\section{Tabelas}

Tabela 1. Relação das consultas de pré-natal, quantidade de consultas realizadas e orientações sobre alimentação e aleitamento materno.

\begin{tabular}{|c|c|c|}
\hline VARIÁVEIS & CONTAGEM & $\%$ \\
\hline Início das consultas de pré-natal: & & 64,6 \\
\hline Primeiro trimestre & 86 & 35,3 \\
\hline Após o primeiro trimestre & 47 & 12,0 \\
\hline Quantidade de consultas realizadas: & 16 & 88,0 \\
\hline 01 a 05 & 117 & 84,2 \\
\hline Recebimento de orientações sobre alimentação & & 15,8 \\
\hline adequada e aleitamento materno. & 112 & 100,0 \\
\hline Sim & 21 & 133 \\
\hline
\end{tabular}

Fonte: Dados da pesquisa. 
Tabela 2. Distribuição do consumo de alimentos ricos em: ferro, ácido fólico e ômega 3.

\begin{tabular}{|c|c|c|}
\hline VARIÁVEIS & CONTAGEM & $\%$ \\
\hline \multicolumn{3}{|c|}{$\begin{array}{l}\text { Consumo de alimentos ricos em ferro como (Carnes, } \\
\text { Feijão e Folhas verde-escuros) durante o pré-natal. }\end{array}$} \\
\hline Sim & 113 & $85,0 \%$ \\
\hline Não & 20 & $15,0 \%$ \\
\hline \multicolumn{3}{|c|}{$\begin{array}{c}\text { Consumo de alimentos ricos em ácido fólico como } \\
\text { (Couve, Brócolis e beterraba)? }\end{array}$} \\
\hline Sim & 85 & $63,9 \%$ \\
\hline Não & 48 & $36,1 \%$ \\
\hline \multicolumn{3}{|c|}{$\begin{array}{l}\text { Consumo de alimentos ricos em ômega } 3 \text { com } \\
\text { (Peixe, salmão, linhaça e Sardinha)? }\end{array}$} \\
\hline Sim & 82 & $61,7 \%$ \\
\hline Não & 51 & $38,3 \%$ \\
\hline Total & 133 & $100 \%$ \\
\hline
\end{tabular}

Fonte: Dados da pesquisa.

Tabela 3. Recebimento de orientações sobre o não consumo de alimentos industrializados, número de refeições realizadas diariamente e diminuição no consumo de fontes de gordura.

\begin{tabular}{|c|c|c|}
\hline VARIÁVEIS & CONTAGEM & $\%$ \\
\hline \multicolumn{3}{|c|}{$\begin{array}{l}\text { Orientação ao não consumo de alimentos } \\
\text { industrializados? }\end{array}$} \\
\hline Sim & 108 & $81,2 \%$ \\
\hline Não & 25 & $18,8 \%$ \\
\hline \multicolumn{3}{|c|}{$\begin{array}{c}\text { Orientação a realização de pelo menos } 5 \\
\text { refeições ao dia? }\end{array}$} \\
\hline Sim & 98 & $73,7 \%$ \\
\hline Não & 35 & $26,3 \%$ \\
\hline \multicolumn{3}{|c|}{$\begin{array}{l}\text { Orientação a diminuição de alimentos fontes de } \\
\text { gorduras durante a gestação? }\end{array}$} \\
\hline Sim & 90 & $67,7 \%$ \\
\hline Não & 43 & $32,3 \%$ \\
\hline Total & 133 & $100 \%$ \\
\hline
\end{tabular}

Fonte: Dados da pesquisa. 
Tabela 4. Suplementação medicamentosa de ferro, zinco, ácido fólico, ômega 3 e vitamina A.

\begin{tabular}{|c|c|c|}
\hline VARIÁVEIS & CONTAGEM & $\%$ \\
\hline \multicolumn{3}{|c|}{$\begin{array}{l}\text { Você foi orientada a tomar ferro na forma de } \\
\qquad \text { comprimido? }\end{array}$} \\
\hline Sim & 128 & $96,2 \%$ \\
\hline Não & 5 & $3,8 \%$ \\
\hline \multicolumn{3}{|c|}{$\begin{array}{l}\text { Você foi orientada a tomar vitamina A na forma } \\
\qquad \text { de comprimido? }\end{array}$} \\
\hline Sim & 33 & $24,8 \%$ \\
\hline Não & 100 & $75,2 \%$ \\
\hline \multicolumn{3}{|c|}{$\begin{array}{l}\text { Você foi orientada a tomar zinco na forma de } \\
\qquad \text { comprimido? }\end{array}$} \\
\hline Sim & 19 & $14,3 \%$ \\
\hline Não & 114 & $85,7 \%$ \\
\hline \multicolumn{3}{|c|}{$\begin{array}{l}\text { Você foi orientada a tomar omega-3 na forma de } \\
\qquad \text { comprimido? }\end{array}$} \\
\hline Sim & 13 & $9,8 \%$ \\
\hline Não & 120 & $90,2 \%$ \\
\hline \multicolumn{3}{|c|}{$\begin{array}{l}\text { Você foi orientada a tomar ácido fólico na forma } \\
\qquad \text { de comprimido? }\end{array}$} \\
\hline Sim & 102 & $76,7 \%$ \\
\hline Não & 31 & $23,3 \%$ \\
\hline Total & 133 & $100 \%$ \\
\hline
\end{tabular}

Fonte: Dados da pesquisa.

Tabela 5. Mudanças na alimentação.

\begin{tabular}{|c|c|c|}
\hline VARIÁVEIS & CONTAGEM & $\%$ \\
\hline Início das consultas de pré-natal: & & 64,6 \\
\hline Primeiro trimestre & 86 & 35,3 \\
\hline Após o primeiro trimestre & 47 & 12,0 \\
\hline Quantidade de consultas realizadas: & 16 & 88,0 \\
\hline 01 a 05 & 117 & 84,2 \\
\hline Recebimento de orientações sobre alimentação & & 15,8 \\
\hline adequada e aleitamento materno. & 112 & 100,0 \\
\hline Sim & 21 & 133 \\
\hline Não & & 8 \\
\hline Total & & \\
\hline
\end{tabular}

Fonte: Dados da pesquisa. 